\title{
Estoques de carbono e nitrogênio em frações da matéria orgânica de solos cultivados com eucalipto nos sistemas convencional e fertirrigado
}

\author{
Stock of carbon and nitrogen in organic matter fractions of soil cultivated with eucalypts in \\ conventional and fertirrigated system
}

\author{
Rodinei Facco Pegoraro Ivo Ribeiro da Silva ${ }^{\text {II }}$ Roberto Ferreira de Novais ${ }^{\text {II }}$ \\ Nairam Felix de Barros" Sebastião Fonseca ${ }^{\text {III }}$
}

\section{RESUMO}

O presente estudo teve o objetivo de avaliar os estoques de $C$ e $N$ nas frações lábeis e estáveis da MOS e da biomassa microbiana em resposta ao cultivo florestal com o uso de fertirrigação quando comparado ao cultivo convencional. Para tanto, duas áreas cultivadas com eucalipto num mesmo solo (Argissolo Amarelo), mas com manejos fertirrigado e convencional foram amostradas nas camadas de 0-10, 10-20, 20-40, 40-60 e 60-100 cm de profundidade na linha e entrelinha de cultivo. A amostragem da entrelinha foi justificada pelo enleiramento e enterro de resíduos vegetais provenientes da colheita do cultivo anterior na entrelinha do cultivo atual. No final do ciclo de cultivo do eucalipto (sete anos), a deposição de serapilheira e os estoques de $\mathrm{C}$ e $\mathrm{N}$ na maioria das frações lábeis e estáveis da MOS foram maiores no sistema fertirrigado, com incremento de 50,34t ha-1 de C total (COT) e 5,62t ha-1 de $N$ total (NT), na camada de 0 $100 \mathrm{~cm}$ de profundidade, em comparação àqueles do sistema convencional. $O$ solo da entrelinha de plantio, principalmente no sistema fertirrigado, apresentou maior estoque de $C$ e $N$ total e $C$ nas frações das substâncias húmicas e na fração leve da MOS que no solo da linha de plantio, possivelmente em virtude da maior deposição e incorporação de resíduos vegetais do ciclo anterior na entrelinha do cultivo atual. A intensificação do manejo de florestas comerciais de eucalipto com o uso de fertirrigação possibilita aumentar a deposição de resíduos vegetais e sequestrar mais $C$ e $N$, tanto em frações estáveis, quanto em frações mais lábeis da MOS, especialmente nas camadas de solo de até $40 \mathrm{~cm}$ de profundidade.

Palavras-chave: substâncias húmicas, sistemas de manejo, resíduos florestais.

\section{ABSTRACT}

The objective of this study was to evaluate the $C$ and $N$ stocks in fractions of labile and more stable SOM fractions in response to intensification of forest cultivation through fertirrigation when compared to conventional stands. To that end, two areas planted with eucalyptus in the same (Ultisol), but with different managements (fertilized and irrigated and conventional system) were sampled in the 0-10, 10-20, 20-40, 40-60 and 60-100 cm deep soil layers in line and interrow of the cultivation. The sampling interrow soil was justified by the ridged and burial of plant residues from previous crop cultivation in-between the substrate. At seven years old, eucalypt under fertirrigation increased the litterfall and the $C$ and $N$ stocks in the most labile and stable SOM fractions, leading to greater stocks of $C$ and $N$ in the $0-100 \mathrm{~cm}$ deep soil layer. The increments due to fertirrigation observed for total $C$ was 50.34 and for the labile fraction was $5.62 t \mathrm{ha}^{-1}$. The eucalypt interrow soil, especially in the fertirrigated treatment, presented larger stocks of total $C$ and $N$ and also larger $C$ stocks in humic substances and light fraction of SOM possibly due to greater deposition and incorporation of vegetable residues from the previous cycle in the interrow current cultivation. The intensification of water and nutrients usage in short-rotation eucalypt stands is an alternative to increase the deposition of vegetable residues and $C$ sequestration in more stable and labile SOM fractions, especially in the $0-40 \mathrm{~cm}$ soil layer.

Key words: humic substances, management systems, forest residues.

\section{INTRODUÇÃO}

O suprimento de água e nutrientes pelo solo é o fator abiótico que mais altera o crescimento do

IDepartamento de Ciências Agrárias (UNIMONTES). Av. Reinaldo Viana, 2630, Bico da Pedra, 39440-000, Janaúba, MG, Brasil.

E-mail: rodinei.pegoraro@unimontes.br. Autor para correspondência.

IDepartamento de Solos, Universidade Federal de Viçosa (UFV), Viçosa, MG, Brasil

IIIAracruz Celulose S.A., Aracruz, ES, Brasil. 
eucalipto nos trópicos (STAPE et al., 2004). A adição desses elementos em solos altamente intemperizados e inférteis tem elevado a produtividade do eucalipto (NEFF et al., 2002; LEGGETT \& KELTING, 2006; STAPE et al., 2006). Além disso, trabalhos têm demonstrado que os estoques de $\mathrm{C}$ e $\mathrm{N}$ nos compartimentos do solo podem aumentar (LEGGETT \& KELTING, 2006; LI et al., 2006) ou diminuir (NEFF et al., 2002) em razão da suplementação de nutrientes. A irrigação também aumenta a produtividade das plantas (STAPE et al., 2006) e pode contribuir para aumentar a MOS (RASSE et al., 2005).

A implantação de manejos mais intensivos de florestas comerciais de eucalipto em curta rotação, com maior adição de nutrientes e água (sistema fertirrigado), favorece maior produção de raízes, madeira (MADEIRA et al., 2002) e aporte de restos vegetais ao solo, podendo aumentar o estoque de $\mathrm{C} \mathrm{e}$ $\mathrm{N}$ nas frações da MOS ao longo do tempo de cultivo. No entanto, a adição de nutrientes para as plantas via solo acelera o processo de decomposição de restos culturais no solo (LEITE et al., 2003), reduzindo os estoques de C e N nas frações lábeis (fração leve) e aumentando nas frações mais humificadas (sustâncias húmicas).

Espera-se que tais mudanças no processo de decomposição ocorram principalmente em solos tropicais, onde a ciclagem da matéria orgânica é mais rápida. Todavia, ainda é necessária a realização de estudos que visem a determinar os efeitos da adubação mineral ou orgânica nos compartimentos da matéria orgânica do solo (LEITE et al., 2003), especialmente em solos cultivados com eucalipto em curta rotação. O presente estudo teve o objetivo de avaliar os estoques de $\mathrm{C}$ e $\mathrm{N}$ em diversas frações da MOS em resposta à intensificação do cultivo florestal por meio da fertirrigação.

\section{MATERIAL E MÉTODOS}

O estudo foi conduzido em cultivos de eucalipto no Município de Aracruz, região litorânea do Estado do Espírito Santo, localizada a 1948'S e $40^{\circ} 17^{\prime} \mathrm{W}$. Foram selecionadas duas áreas de cultivo de eucalipto, uma cultivada em sequeiro e caracterizada como sistema convencional e a outra fertirrigada caracterizada como sistema fertirrigado. Essas áreas foram constituídas dos tratamentos no plantio atual: solo da linha em sistema convencional de cultivo de eucalipto $\left(E C_{L}\right)$; solo da entrelinha em sistema convencional de cultivo de eucalipto $\left(\mathrm{EC}_{\mathrm{EL}}\right)$; solo da linha em sistema fertirrigado de cultivo de eucalipto $\left(E F_{L}\right)$; e solo na entrelinha em sistema fertirrigado de cultivo de eucalipto $\left(\mathrm{EF}_{\mathrm{EL}}\right)$.
O solo foi caracterizado como Argissolo Amarelo fase floresta tropical subperenifólia, textura média sobre argilosa, derivado do grupo Barreiras. A área de estudo foi cultivada com eucalipto durante 28 anos (quatro rotações). No período prévio à montagem do estudo, amostras de solo foram coletadas na época chuvosa (janeiro/fevereiro) para caracterização física e química: $\mathrm{pH}\left(\mathrm{H}_{2} \mathrm{O}\right)=5,1 ; \mathrm{Ca}^{2+}=1,4 \mathrm{cmol}_{\mathrm{c}} \mathrm{dm}^{-3} \mathrm{e}$ $\mathrm{Mg}^{2+}=0,3 \mathrm{cmol} \mathrm{dm}^{-3}\left(\mathrm{KCl}-1 \mathrm{~mol} \mathrm{~L}^{-1}\right) ; \mathrm{H}+\mathrm{Al}=2,6 \mathrm{cmol} \mathrm{dm}^{-3}$ (acetato de cálcio 0,5mol L-1-pH 7,0); $\mathrm{P}=14,2 \mathrm{mg} \mathrm{dm}^{-3} \mathrm{e}$ $\mathrm{K}=25,8 \mathrm{mg} \mathrm{dm}^{-3}$ (Mehlich 1); areia=75\%; silte=3\%; argila $=22 \%$ e densidade $=1,4 \mathrm{~kg} \mathrm{dm}^{-3}$.

O preparo do solo para o plantio de eucalipto foi realizado mediante gradagem (bedding), momento em que os resíduos da colheita foram enterrados com a massa de solo na direção da linha de cepas (tocos) do cultivo anterior e, em seguida, o solo foi coveado e o eucalipto plantado e fertilizado com $100 \mathrm{~g} \mathrm{cova}^{-1}$ de adubo mineral na formulação NPK 06-30-06. O plantio das mudas de eucalipto foi realizado em 1998, com mudas clonais do híbrido Eucalyptus grandis x $\boldsymbol{E}$. urophylla, cultivado em sistema de reforma, espaçamento 3x3m. Após 90 dias do plantio, os tratamentos no sistema convencional receberam $350 \mathrm{~kg}$ $\mathrm{ha}^{-1}$ de fosfato natural a lanço e, no final do primeiro ano, mais $160 \mathrm{~kg} \mathrm{ha}^{-1}$ de NPK 6-30-6. Já as plantas cultivadas no sistema fertirrigado foram adubadas com $600 \mathrm{~kg} \mathrm{ha}^{-1}$ de Ca e $300 \mathrm{~kg} \mathrm{ha}^{-1}$ de $\mathrm{Mg}$ (como calcário dolomítico); $4 \mathrm{~kg} \mathrm{ha}^{-1} \mathrm{de} \mathrm{B}, 2 \mathrm{~kg} \mathrm{ha}^{-1}$ de Cu e $2 \mathrm{~kg} \mathrm{ha}^{-1}$ de Zn (como FTE), seguido por fertilizações trimestrais com $126 \mathrm{~kg} \mathrm{ha}^{-1} \mathrm{~N}$ (como sulfato de amônio), $21 \mathrm{~kg} \mathrm{ha}^{-1}$ de $\mathrm{P}$ (como superfosfato simples) e $79 \mathrm{~kg} \mathrm{ha}^{-1} \mathrm{~K}$ (como cloreto de potássio) (STAPE et al., 2004).

No final do ciclo de cultivo (sete anos), foram coletadas, na linha e entrelinha do eucalipto, três amostras compostas de solo (quatro amostras simples) nas profundidades de 0-10, 10-20, 20-40, 40-60 e 60$100 \mathrm{~cm}$. Em cada talhão, por meio de abertura de trincheiras, foram coletadas amostras indeformadas com anéis volumétricos para se estimar a densidade aparente do solo. A coleta de amostras na linha e entrelinha do solo deveu-se ao fato de ter sido verificado maior acúmulo e enterro pela grade bedding de resíduos vegetais da colheita do eucalipto do ciclo anterior na atual entrelinha de cultivo.

Em todas as amostras coletadas foram efetuadas análises de carbono orgânico total (COT), nitrogênio total (NT), C e N das substâncias húmicas: frações ácidos fúlvicos, ácidos húmicos, huminas e o somatório das três frações (substâncias húmicas-SH). Também foram feitas determinações do C e N da matéria orgânica leve (Fração leve), C da biomassa microbiana (C-BM) e $\mathrm{N}$ da biomassa microbiana (N-BM). 
Determinação do carbono orgânico total e nitrogênio total do solo

Amostras de solo (TFSA) foram trituradas e passadas em peneira de 100 mesh $(0,149 \mathrm{~mm})$ para determinação de COT pelo método de oxidação via úmida, com aquecimento externo (YEOMANS \& BREMNER, 1988). O NT foi determinado por destilação após digestão sulfúrica (BATAGLIA et al., 1983).

Fracionamento de substâncias húmicas

O fracionamento de substâncias húmicas foi realizado segundo o método sugerido pela International Humic Substances Society (SWIFT, 1996). Desse fracionamento, obtiveram-se as frações ácidos fúlvicos (FAF), ácidos húmicos (FAH) e huminas (FH). Do somatório de todas essas frações húmicas, foram obtidas as substâncias húmicas (SH). A determinação de $\mathrm{C}$ e $\mathrm{N}$, em cada fração húmica, foi realizada conforme YEOMANS \& BREMNER (1988) e BATAGLIA et al. (1983), respectivamente.

Separação da matéria orgânica leve (MOL) e quantificação do carbono (C-MOL) e nitrogênio ( $N$ MOL)

O método consistiu em agitar manualmente $13 \mathrm{~g}$ de amostra de solo seco e peneirado ( $2 \mathrm{~mm}$ ), provenientes das diferentes profundidades, com $30 \mathrm{~mL}$ de iodeto de sódio (densidade 1,8kg L-1), em tubo de centrífuga de $50 \mathrm{~mL}$. Em seguida, as amostras foram centrifugadas a $2.400 \mathrm{~g}$ por $15 \mathrm{~min}$, e o material orgânico sobrenadante foi coletado em peneira de 100 mesh, o qual constituiu a fração da matéria orgânica leve (MOL). Os teores de C e $\mathrm{N}$ na fração leve foram determinados por combustão via seca em analisador elementar CHNS (Perkin Elmer).

Determinação do carbono e nitrogênio da biomassa microbiana do solo

Amostras de solo (TFSA) foram pesadas e acondicionadas em copos plásticos com tampas perfuradas e incubadas, com umidade a $60 \%$ da capacidade de campo (-33kPa), em ambiente controlado sob temperatura de $20^{\circ} \mathrm{C}$ por 10 dias, para permitir o restabelecimento da comunidade microbiana. Depois do período de incubação, procedeu-se à determinação do $\mathrm{C}$ da biomassa microbiana (C-BM) pelo método da irradiação e extração (ISLAM \& WEIL, 1998) e do N da BM (N-BM) por destilação após digestão sulfúrica (BATAGLIA et al., 1983).

Ao final, foram estimados os estoques de C e $\mathrm{N}$ nas distintas camadas e na camada de $0-100 \mathrm{~cm}$ do solo (somatório de todas as camadas). Para tanto, utilizou-se a correção da densidade do solo segundo equação expressada matematicamente por SISTI et al. (2004). O solo de referência (com menor densidade) utilizado foi aquele de eucalipto, linha de plantio.

A serapilheira na superfície do solo foi quantificada no momento da coleta das amostras de solo da seguinte forma: para cada tratamento, foram selecionados e coletados quatro pontos, utilizando-se um gabarito com $0,25 \mathrm{~m}^{2}$ de área $(0,5 \times 0,5 \mathrm{~m})$. Após a coleta, as amostras de serrapilheira foram secadas em estufa $\left(65^{\circ} \mathrm{C}\right.$ por $\left.72 \mathrm{~h}\right)$ e separadas em galhos, casca, folhas e outros componentes não identificados para determinação da matéria seca.

O delineamento experimental foi em DBC, com quatro repetições. Os tratamentos foram alocados na parcela principal, e as profundidades foram alocadas nas subparcelas. O teste de médias adotado foi o LSD de Fischer ( $\mathrm{P}<5 \%$ ) protegido (STEEL et al., 1997), ou seja, foram realizadas comparações múltiplas apenas quando o teste de $\mathrm{F}$ da análise de variância foi significativo $(\mathrm{P}<5 \%)$. A expressão tendência foi adotada para as variáveis estoque de $\mathrm{C}$ e $\mathrm{N}$ da MOL quando obteve-se significância de $>5 \%$ e $<20 \%$ no teste de F da análise de variância.

\section{RESULTADOS E DISCUSSÃO}

Estoques de carbono orgânico total, nitrogênio total e carbono e nitrogênio nas frações das substâncias húmicas

O sistema de cultivo fertirrigado aumentou os estoques de $\mathrm{C}$ orgânico total (COT) e $\mathrm{N}$ total e as frações das substâncias húmicas em cada camada (0$10,10-20,20-40,40-60$ e 60-100cm) e na camada de 0$100 \mathrm{~cm}$ de profundidade. Nessa última camada $(0-$ $100 \mathrm{~cm}$ ), o aumento foi de 50,34 e 5,62t ha ${ }^{-1}$ de C e N no solo de eucalipto fertirrigado em comparação ao do sistema convencional (Figuras 1 e 2). Esse incremento, provavelmente, deveu-se ao maior aporte de $\mathrm{C}$ e $\mathrm{N}$ ao solo, pois a fertirrigação aumentou a deposição de serapilheira em mais de $60 \%$ : galhos (eucalipto convencional $=8,2 \mathrm{t} \mathrm{ha}^{-1}$ e eucalipto fertirrigado $\left.=9,1 \mathrm{tha}^{-1}\right)$; casca, folhas e outros componentes (eucalipto convencional $=6,0 \mathrm{t} \mathrm{ha}^{-1}$ e eucalipto fertirrigado $=14,0 \mathrm{t}$ $\mathrm{ha}^{-1}$ ), totalizando $23,1 \mathrm{t} \mathrm{ha}^{-1}$ no cultivo convencional $14,2 \mathrm{tha}^{-1}$ e no cultivo fertirrigado. MADEIRA et al. (2002) verificaram que, após seis anos de cultivo do $\boldsymbol{E}$. globulus Labill., houve acúmulo de C na planta (parte aérea e raiz) de $9,71 \mathrm{~kg} \mathrm{~m}^{-2}$ no tratamento irrigado mais fertilizado e este foi 1,2; 1,4 e 1,8 vezes maior que nos solos dos tratamentos irrigado, fertilizado e controle, respectivamente.

Ciência Rural, v.40, n.2, fev, 2010. 


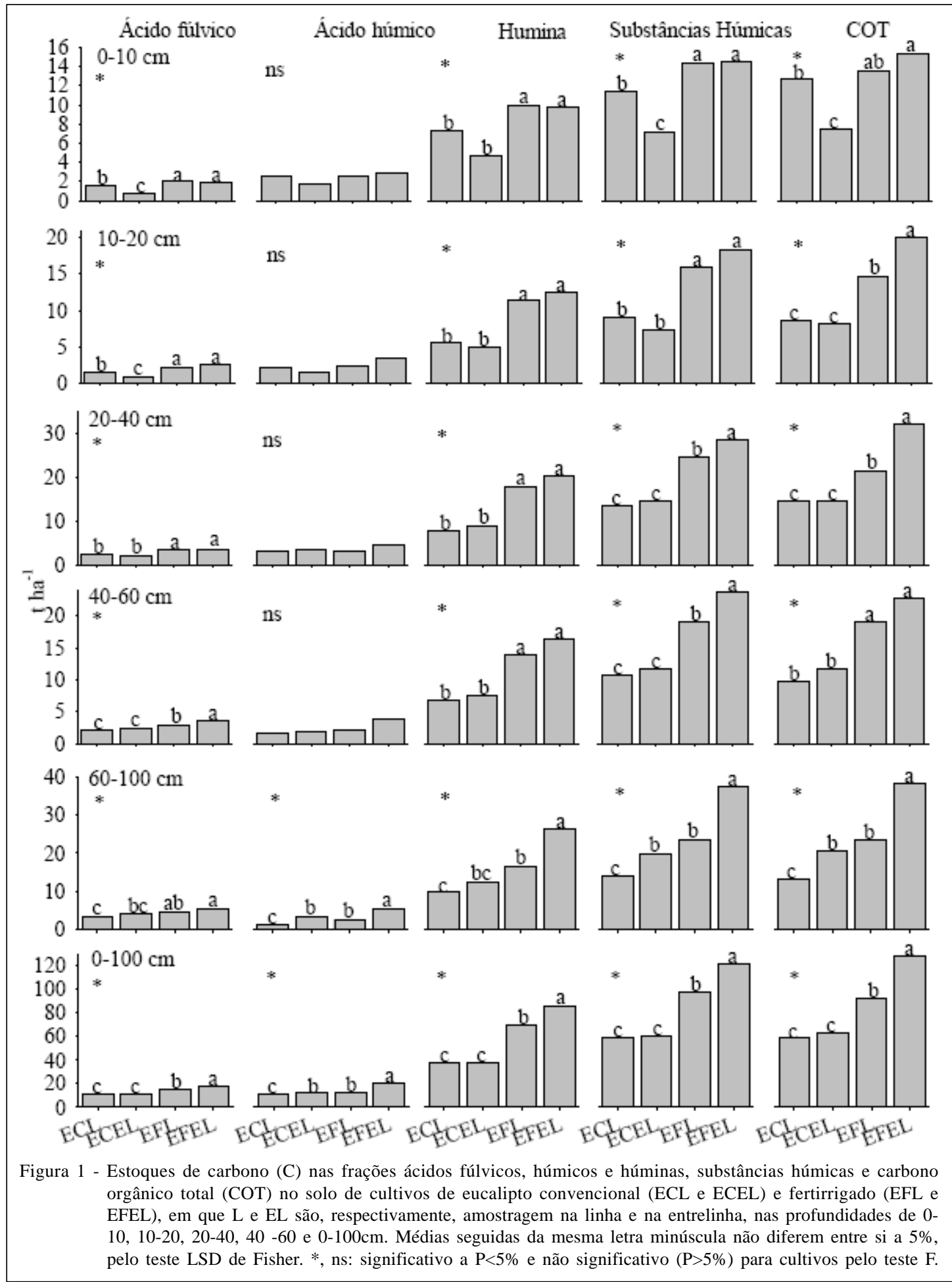

A irrigação mais a fertilização também foi o tratamento que apresentou maior eficiência no incremento do $\mathrm{C}$ no solo após seis anos de cultivo do E. globulus Labill, com $11,40 \mathrm{~kg} \mathrm{~m}^{-2}$, em comparação ao sistema irrigado $\left(8,87 \mathrm{~kg} \mathrm{~m}^{-2}\right)$, ao fertilizado $\left(7,86 \mathrm{~kg} \mathrm{~m}^{-2}\right)$ e à testemunha $\left(5,86 \mathrm{~kg} \mathrm{~m}^{-2}\right)$. Esse resultado justifica-se pelo aumento da produção de raízes, compartimento que pode aumentar o tempo médio de residência do $\mathrm{C}$ no solo em 2,4 vezes e o estoque de C na MOS, em 


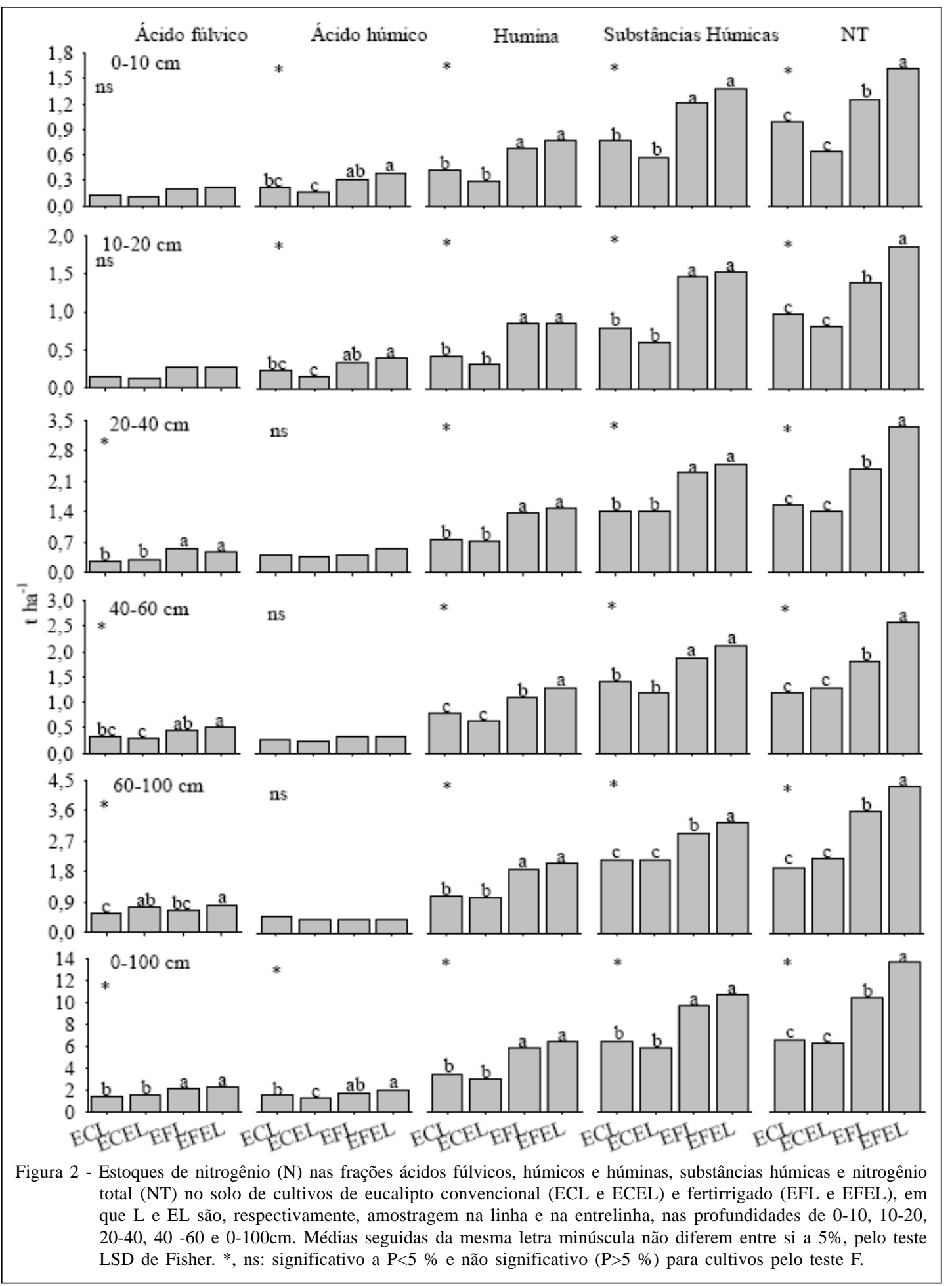

compração ao $C$ derivado da parte aérea das plantas (RASSE et al., 2005).

No solo da entrelinha do eucalipto em sistema fertirrigado, também se verificou maior estoque de C e $\mathrm{N}$ total na camada de $0-100 \mathrm{~cm}$, em comparação ao solo na linha de plantio (Figuras 1 e 2), possivelmente em decorrência da maior deposição de resíduos vegetais da colheita na entrelinha de cultivo e da maior eficiência para converter resíduos em MOS e substâncias húmicas. No solo de eucalipto 
convencional, essas diferenças entre amostras coletadas na linha e na entrelinha foram pouco expressivas para as frações humificadas da MOS, mesmo com o enterramento dos resíduos da colheita, indicando menor eficiência desse manejo em aumentar o estoque de $\mathrm{C}$, em comparação ao do manejo fertirrigado.

No sistema fertirrigado, obteve-se maior proporção de materiais menos grosseiros, como folhas e galhos finos na serapilheira, o que pode favorecer mais rápida degradação dos resíduos vegetais. Esses resíduos apresentam menor teor de lignina no seu tecido vegetal do que galhos grossos (PEGORARO, 2007) e, aliados à maior adição de água e fertilizantes, podem ter contribuído com a tendência de redução no estoque de C, na fração leve da MOS, no sistema fertirrigado. LI et al. (2006) verificaram aumento de 13\% na decomposição de folhas de liteira em relação ao tratamento controle (sem fertilização). Porém, a fertilização, principalmente com adição de $\mathrm{N}$, pode auxiliar diretamente na estabilização de formas orgânicas do C no solo, aumentando, também, os estoques de $\mathrm{C}$ e $\mathrm{N}$ em frações mais humificadas da MOS, conforme verificado no sistema fertirrigado. NEFF et al. (2002) demonstraram que a fertilização com N acelerou a decomposição das frações leves da matéria orgânica com tempos de ciclagem em torno de décadas, mas auxiliou na estabilização das frações de $\mathrm{C}$ das substâncias húmicas associados à fração mineral e que possuem tempo de ciclagem de décadas (STEVENSON, 1994). Tal hipótese é corroborada pelo incremento nos estoques de $\mathrm{N}$ nas substâncias húmicas, em especial nos ácidos húmicos e huminas (Figura 2).

Estoques de carbono e nitrogênio na fração leve e biomassa microbiana do solo

Os maiores estoques de $\mathrm{C}$ e $\mathrm{N}$ na fração leve da matéria orgânica (MOL) e da biomassa microbiana (BM) foram encontrados nas camadas superficiais do solo, provavelmente em decorrência da maior deposição de raízes (RASSE et al., 2005) e resíduos da parte aérea do eucalipto (Figura 3), substratos para a comunidade microbiana do solo. $\mathrm{O}$ estoque de $\mathrm{C}$ e $\mathrm{N}$ da MOL, nas camadas de solo até 0 $100 \mathrm{~cm}$ de profundidade, foi semelhante $(\mathrm{P}>0,05)$ entre os cultivos, com exceção da camada de $40-60 \mathrm{~cm}$, em que se obteve maior estoque de $\mathrm{C}$ e $\mathrm{N}$ no solo de entrelinha do eucalipto fertirrigado e estoque de $\mathrm{N}$ nas camadas de 10-20 e 20-40 no solo da entrelinha e linha do eucalipto convencional. Verificou-se tendência $(\mathrm{P}<0,2)$ de o cultivo fertirrigado causar redução no estoque de $C$ na MOL, nas camadas superficiais do solo (0-10 e 10-20cm), em comparação ao solo de eucalipto convencional (Figura 3). Esse resultado pode estar associado à maior atividade microbiana no solo, estimulada pela maior disponibilidade de água e nutrientes adicionados via fertirrigação.

O processo de mineralização dos resíduos vegetais pode ser acelerado com a maior disponibilidade de água e nutrientes. DE BONA et al. (2006) obtiveram aumentos de 19 e $15 \%$ na taxa de decomposição de resíduos de aveia $\left(\mathrm{k}_{1}\right)$ e da MOS $\left(\mathrm{k}_{2}\right)$, respectivamente, em solo cultivado com aveia no sistema irrigado, em comparação ao sistema não irrigado, na camada de 0$20 \mathrm{~cm}$ de profundidade. O aumento na taxa de decomposição de resíduos vegetais pode incrementar os estoques de $\mathrm{C}$ e $\mathrm{N}$ das frações mais lábeis (C lábil) e estáveis (substâncias húmicas) da MOS. O aumento da disponibilidade dos resíduos vegetais de palha de arroz (MORAN et al., 2005), de cana-de-açúcar (GRAHAM et al., 2002) e da adubação com N mineral aumenta o estoque de $C$ lábil e contribui para o aumento do $\mathrm{C}$ na fração humina, compartimento tido como o mais estável das SH (DIJKSTRA et al., 2004).

A deposição e incorporação de resíduos vegetais do eucalipto na entrelinha aumentou o estoques de $\mathrm{C}$ e $\mathrm{N}$ da biomassa microbiana nas camadas inferiores do solo $(40-60 \mathrm{~cm}$ de profundidade), no sistema fertirrigado (Figura 3), indicando a possível existência de maior disponibilidade de alimento para os microrganismos na entrelinha e, em profundidade, devido ao maior aporte de resíduos vegetais da colheita anterior (parte aérea e raízes).

Na camada de $0-60 \mathrm{~cm}$, o estoque de $\mathrm{C}$ e $\mathrm{N}$ na biomassa microbiana do solo da entrelinha, no sistema fertirrigado, foi maior do que no sistema convencional, bem como foi maior o estoque de $\mathrm{C}$ e $\mathrm{N}$ nas substâncias húmicas, indicando uma maior conversão de resíduos vegetais depostos no solo em compostos orgânicos mais estáveis. Presumidamente, dois fatores principais podem ter contribuído para ocorrência de tais resultados: 1) a maior presença de água e nutrientes (N) no sistema fertirrigado, estimulando a atividade microbiana no solo e a decomposição dos resíduos vegetais não lignificados (compostos orgânicos carbonados solúveis e holocelulose não lignificada) (MORAN et al., 2005), dando origem a produtos secundários (compostos fenólicos, aminoácidos, aminoaçúcares, etc.) capazes de formar complexos organo-metálicos estáveis com os minerais do solo (argila) e aumentando sua preservação e seu acúmulo em frações protegidas (DEVÊVRE \& HORWÁTH, 2001) e quimicamente recalcitrantes; e 2) a atuação do N mineral do solo como importante precursor na estabilização de compostos orgânicos parcialmente decompostos e mais 


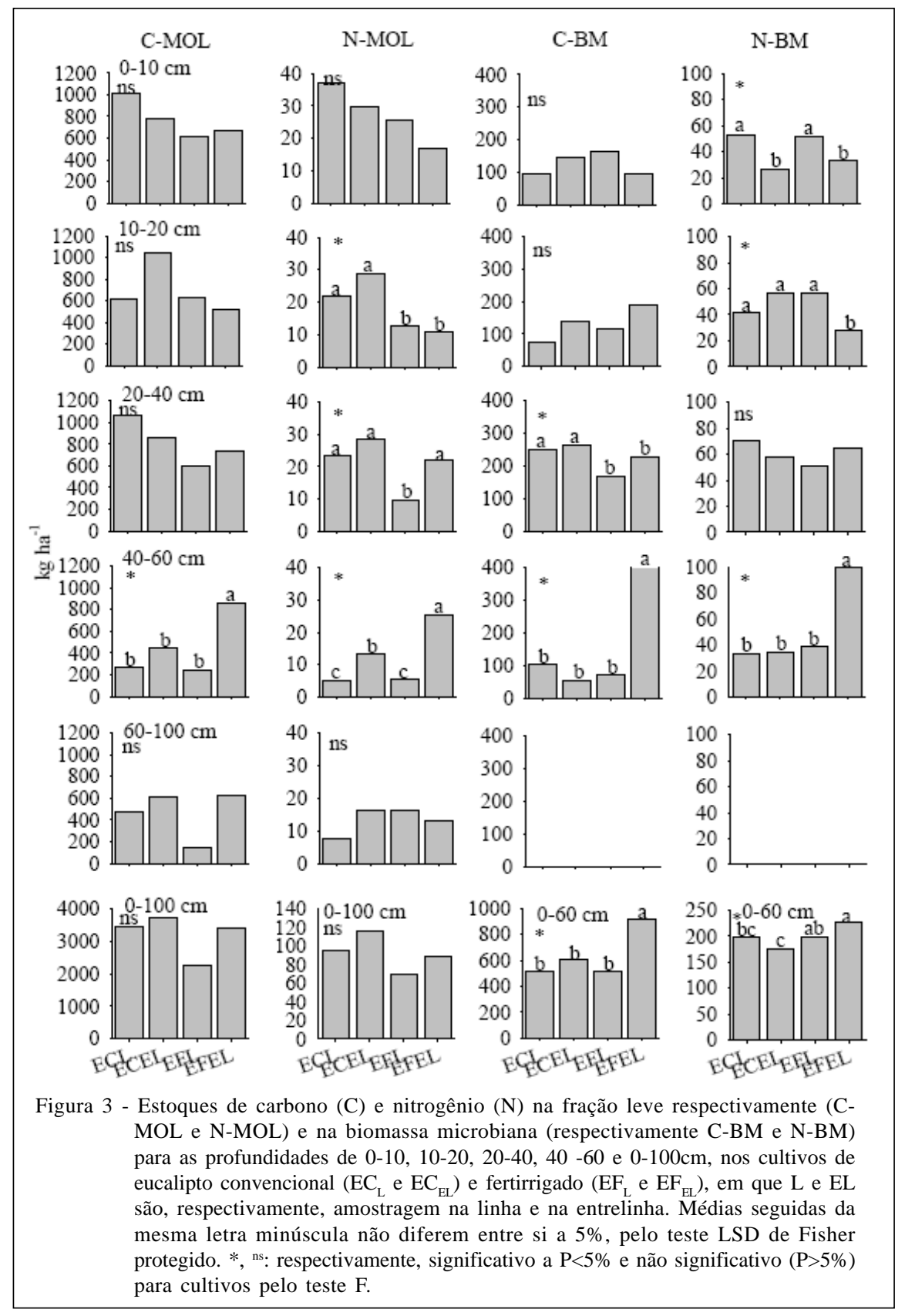

recalcitrantes, abundantes em resíduos vegetais de eucalipto, favorecendo seu acúmulo nas substâncias húmicas, pela sua menor suscetibilidade à ação de enzimas lignolíticas (NEFF et al., 2002).

\section{CONCLUSÕES}

O sistema de cultivo fertirrigado leva à redução nos estoques de $\mathrm{C}$ e $\mathrm{N}$ da fração leve da matéria orgânica do solo em comparação ao sistema convencional. A intensificação do sistema de manejo de florestas comerciais de eucalipto com o uso de fertirrigação aliado ao enterro de resíduos da colheita possibilita o aumento do estoque de $\mathrm{C}$ orgânico e $\mathrm{N}$ total, $\mathrm{C}$ e $\mathrm{N}$ na biomassa microbiana, nas substâncias húmicas e em suas frações, especialmente nas camadas de solo de até $40 \mathrm{~cm}$ de profundidade.

\section{AGRADECIMENTOS}

À FAPEMIG e ao CNPq pelo auxílio financeiro na forma de concessão de bolsas de incentivo e pesquisa e Doutorado, respectivamente.

Ciência Rural, v.40, n.2, fev, 2010. 


\section{REFERÊNCIAS}

BATAGLiA, O.C. et al. Métodos de análises químicas de plantas. Campinas: Instituto Agronômico, 1983. 48p. (Boletim, 78).

DE BONA, F.D. et al. Carbono orgânico no solo em sistemas irrigados por aspersão sob plantio direto e preparo convencional. Revista Brasileira de Ciência do Solo, v.30, p.911-920, 2006. Disponível em: <http://www.scielo.br/scielo.php?script=sci_arttext\&pid=S010006832006000500017>. Acesso em: 29 out. 2009. doi: 10.1590/ S0100-06832006000500017.

DEVÊVRE, O.C.; HORWÁTH, W.R. Stabilization of fertilizer nitrogen-15 into humic substances in aerobic vs. waterlogged soil following straw incorporation. Soil Science Society of America Journal, v.65, p.499-510, 2001. Disponível em: <http://soil.scijournals. org /cgi/content/abstract/65/2/499>. Acesso em: 29 out. 2009.

DIJKSTRA, F.A. et al. Nitrogen deposition and plant species interact to influence soil carbon stabilization. Ecology Letters, v.7, p.1192-1198. 2004. Disponível em: <http:// www.springerlink.com/content/18m8r2v706425242/>. Acesso em: 29 out. 2009. doi: 10.1007/s10533-009-9321-0.

GRAHAM, M.H. et al. Soil organic matter content and quality: effects of fertilizer application, burning and trash retention on a long-term sugarcane experiment in South Africa. Soil Biology and Biochemical, v.34, p.93-102, 2002. Disponível em: <http://www. sciencedirect.com>. Acesso em: 29 out. 2009. doi: 10.1016/S0038-0717(01)00160-2.

ISLAM, K.R.; WEIL, R.R. Microwave irradiation of soil for routine measurement of microbial biomass carbon. Biology and Fertility of Soils, v.27, p.408-416, 1998. Disponível em: <http://www.springerlink.com/content/ecfkd546qwjkfuup/> Acesso em: 29 out. 2009. doi: 10.1007/s003740050451.

LEGGETT, Z.H.; KELTING, D.L. Fertilization effects on carbon pools in loblolly pine plantations on two upland sites. Soil Science Society of America Journal, v.70, p.279286, 2006. Disponível em: <http://soil.scijournals.org/cgi/ content/full/70/1/279>. Acesso em: 29 out. 2009. doi: 10.2136/ sssaj2003.0232.

LEITE, L.F.C. et al. Estoques totais de carbono orgânico e seus compartimentos em Argissolo sob floresta e sob milho cultivado com adubação mineral e orgânica. Revista Brasileira de Ciência do Solo, v.27, p.821-832, 2003. Disponível em: <http://www.scielo.br/pdf/rbcs/v27n5/v27n5a06.pdf >. Acesso em: 29 out. 2009. doi: 10.1590/S0100-06832008000100030.

LI, Y. et al. Effects of nutrient additions on ecosystem carbon cycle in a Puerto Rican tropical wet forest. Global Change Biology, v.12, p.284-293, 2006. Disponível em: <http:// www3.interscience.wiley.com/journal/118575675/ abstract?CRETRY=1\&SRETRY=0>. Acesso em: 29 out. 2009. doi: 10.1111/j.1365-2486.2005.01096.x.

MADEIRA, M.V. et al. Changes in carbon stocks in Eucalyptus globulus Labill. plantations induced by different water and nutrient availability. Forest Ecology and Management, v.171, p.7585, 2002. Disponível em: <http://www.sciencedirect.com/>. Acesso em: 28 out. 2009. doi:10.1016/S0378-1127(02)00462-0.

MORAN, K.K. et al. Role of mineral nitrogen in residue decomposition and stable soil organic matter formation. Soil Science Society of America Journal, v.69, p.1730-1736, 2005. Acesso em: <http://soil.scijournals.org/cgi/content/abstract/ 69/6/1730>. Acesso em: 28 out. 2009. doi: 10.2136/sssaj2004.0301.

NEFF, J.C. et al. Variable effects of nitrogen additions on the stability and turnover of soil carbon. Nature, v.419, p.915917, 2002. Disponível em: <http://www.nature.com/nature/ journal/v419/n6910/abs/nature01136.html>. Acesso em: 28 out. 2009

PEGORARO, R.F. Seqüestro de carbono e alterações bioquímicas da matéria orgânica de solos cultivados com eucalipto. 2007. 140f. Tese (Doutorado em Solos e Nutrição de Plantas) - Pós-Graduação em Solos e Nutrição de Plantas, Universidade Federal de Viçosa, MG.

RASSE, D.P. et al. Is soil carbon mostly root carbon? Mechanisms for a specific stabilization. Plant Soil, v.269, p.341-356, 2005. Disponível em: <http://www.springerlink. com/content/1543334m54177x4t/>. Acesso em: 28 out. 2009. doi:10.1007/s11104-004-0907y.

SISTI, C.P.J. et al. Change in carbon and nitrogen stocks in soil under 13 years of conventional or zero tillage in southern Brazil. Soil \&Tillage Research, v.76, p.39-58, 2004. Disponível em: <http://www.sciencedirect.com/>. Acesso em: 22 set. 2008. doi:10.1016/j.still.2003.08.007.

STAPE, J.L. et al. A twin-plot approach to determine nutrient limitation and potential productivity in Eucalyptus plantations at landscape scales in Brazil. Forest Ecology and Management, v.223, p.358-362, 2006. Disponível em: <http:/ /www.sciencedirect.com/>. Acesso em: 22 set. 2008. doi:10.1016/j.foreco.2005.11.015.

STAPE, J.L. et al. Testing the utility of the 3-PG model for growth of Eucalyptus grandis x urophylla with natural and manipulated supplies of water and nutrients. Forest Ecology and Management, v.193, p.219-234, 2004.

STEEL, R.G.D. et al. Principles and procedures of statistics: a biometrical approach. New York: McGrawHill, 1997. 666p.

STEVENSON, F.J. Humus chemistry: genesis, composition and reactions. 2.ed. New York, Willey \& Sons, 1994. 496p.

SWIFT, R.S. Organic matter characterization. In: SPARKS, D.L. et al. Methods of soil analysis. Madison: SSSA, 1996. Cap.3, p.1011-1069.( Book Series n.5).

YEOMANS, J.C.; BREMNER, J.M. A rapid and precise method for routine determination of organic carbon in soil. Communications in Soil Science and Plant Analysis, v.13, p.1467-1476, 1988. Disponível em: <http:// www.informaworld.com/smpp/content $\sim$ content $=$ a905376787 $\mathrm{db}=\mathrm{all}>$. Acesso em: 22 set. 2008. doi: 10.1080/ 00103628809368027. 